\title{
Prevalensi malaria di Asmat, Papua: Gambaran situasi terkini di daerah endemik tinggi
}

\author{
Josephine Debora, ${ }^{1}$ Hanggoro Tri Rinonce, ${ }^{2}$ Maria Fransiska Pudjohartono, ${ }^{1}$ Pritania Astari, ${ }^{1}$ \\ Monica Gisela Winata, ${ }^{1}$ dan Fadli Kasim ${ }^{3}$ \\ ${ }^{1}$ Mahasiswa Program Studi Profesi Dokter, Fakultas Kedokteran, Kesehatan Masyarakat, dan \\ Keperawatan, Universitas Gadjah Mada, Yogyakarta, Indonesia \\ ${ }^{2}$ Departemen Patologi Anatomik, Fakultas Kedokteran, Kesehatan Masyarakat, dan Keperawatan, \\ Universitas Gadjah Mada, Yogyakarta, Indonesia \\ ${ }^{3}$ Departemen Teknik Nuklir dan Teknik Fisika, Fakultas Teknik, Universitas Gadjah Mada, Yogyakarta, \\ Indonesia
}

Submitted: 30 September 2018 Revised: 18 Oktober 2018 Accepted: 6 November 2018

\begin{abstract}
ABSTRAK Malaria merupakan salah satu penyakit yang terus endemik di beberapa daerah di Indonesia walaupun pemerintah telah melakukan berbagai usaha untuk mengobati dan mencegah malaria. World Health Organization (WHO) menargetkan insidensi kasus malaria pada tahun 2030 dapat turun hingga $90,0 \%$ dibandingkan tahun 2015. Asmat merupakan salah satu daerah endemik tinggi dan menjadi salah satu daerah target program eliminasi malaria, namun belum ada publikasi data rinci terkait malaria di Asmat, Papua. Penelitian ini bertujuan untuk mengetahui prevalensi malaria di Asmat pada tahun 2017 dan melihat tren kejadian malaria yang merupakan salah satu indikator evaluasi program eliminasi malaria di Indonesia. Penelitian ini merupakan penelitian deskriptif observasional yang dilakukan selama pelaksanaan kegiatan Kuliah Kerja Nyata - Peduli Bencana (KKN-PB) Universitas Gadjah Mada (UGM), pada tanggal 17 Maret hingga 30 April 2018 di Asmat, Papua. Penelitian dilakukan dengan analisis data sekunder dan observasi. Data sekunder diambil dari Dinas Kesehatan Kabupaten Asmat, kemudian dianalisis dan dipaparkan secara deskriptif. Dilakukan pula observasi lingkungan di Distrik Agats, Atsj, dan Sawaerma untuk mengetahui kemungkinan faktor-faktor risiko malaria. Pada tahun 2017, prevalensi malaria di kabupaten Asmat yaitu 12,4\% dengan 7,9\% kasus malaria klinis dan 4,5\% kasus malaria yang telah tegak diagnosisnya berdasarkan hasil pemeriksaan laboratorium. Prevalensi tersebut meningkat dibandingkan tahun 2016. Pusat Kesehatan Masyarakat (Puskesmas) Atsj merupakan puskesmas dengan prevalensi malaria tertinggi, yaitu sebesar 27,7\%. Kejadian malaria ini kemungkinan dipengaruhi oleh lingkungan fisik (suhu, kelembaban, kerapatan dinding rumah, penggunaan kawat kassa, curah hujan), lingkungan biologi (adanya semak dan rawa), lingkungan kimia (salinitas dan $\mathrm{pH}$ ), serta kebiasaan masyarakat. Hasil penelitian ini menunjukkan bahwa penanganan malaria di Asmat masih menjadi tantangan besar bagi petugas kesehatan dan pemerintah. Diperlukan penelitian lebih lanjut untuk mengetahui faktor penyebab pasti masih tingginya kejadian malaria agar kebijakan yang diambil lebih tepat.
\end{abstract}

KATA KUNCI prevalensi; malaria; endemik; Asmat; Papua

ABSTRACT Malaria is still an endemic disease in Indonesia, despite years of government efforts to cure and prevent malaria. World Health Organization (WHO) has a goal to reduce malaria case incidence globally at least $90.0 \%$ in 2030 compared with 2015. Asmat is one of the high endemic areas in Indonesia, making Asmat one of the target areas for malaria elimination programs. However, the published data regarding

*Corresponding author: Josephine Debora

Fakultas Kedokteran, Kesehatan Masyarakat, dan Keperawatan, Universitas Gadjah Mada, Jl. Farmako, Sekip Utara, Yogyakarta 55281, Indonesia

E-mail: josephine.debora.u@mail.ugm.ac.id 
malaria in Asmat is limited. This study aimed to investigate the prevalence of malaria in Asmat in 2017 and assess the trend of malaria prevalence, as an indicator in evaluating malaria elimination programs. This study was descriptive observational research which was performed from March $17^{\text {th }}$ until April $30^{\text {th }}$ 2018, as part of Kuliah Kerja Nyata - Peduli Bencana (KKN-PB) Universitas Gadjah Mada (UGM), in Asmat Regency. This study was using secondary data analysis and environmental observation. Secondary data was obtained from Department of Health in Asmat Regency and presented descriptively. Environmental observation in Agats, Atsj, and Sawaerma District was also conducted to find out the possible risk factors of malaria. In 2017, malaria prevalence in Asmat was $12.4 \%$ with $7.9 \%$ cases being clinically diagnosed malaria, and the other 4.5\% laboratory diagnosed malaria. The prevalence in 2017 was higher than in 2016. Among all the districts in Asmat, Atsj had the highest prevalence (27.7\%). Malaria prevalence was possibly affected by multiple factors, such as physical environment (temperature, humidity, houses' wall density, and the use of wire net), biological environment (house surrounded by bush or swamp), chemical environment ( $\mathrm{pH}$ and salinity), and habits in community. These findings suggest that malaria control is still a big challenge for health-care workers and government. Further research is needed to study the exact causes of high malaria prevalence in Asmat, so that more appropriate policies can be done to overcome the problem.

KEYWORDS prevalence; malaria; endemic; Asmat; Papua

\section{Pendahuluan}

Sustainable development goal (SDG) tahun 2015 menetapkan malaria menjadi salah satu penyakit yang menjadi target eliminasi epidemi pada tahun 2030, selain AIDS dan tuberkulosis, serta neglected tropical disease. Target yang ditetapkan antara lain pada tahun 2030 mortalitas dan insidensi kasus malaria dapat turun hingga 90,0\% dibandingkan tahun 2015 serta mengeliminasi malaria pada minimal 35 negara. World Health Organization (WHO) telah menetapkan global technical strategy for malaria 2016-2030 yaitu strategi pencegahan dan pengobatan untuk mencapai target, dan menetapkan data insidensi malaria per tahun (annual malaria incidence/ AMI) sebagai salah satu indikator yang dapat digunakan untuk evaluasi. Pada tahun 2016 diperkirakan terdapat 216 juta kasus malaria di seluruh dunia, meningkat 5 juta kasus dibandingkan tahun 2015. ${ }^{1,2}$

Malaria yang ditularkan melalui gigitan nyamuk Anopheles merupakan salah satu penyakit yang tetap endemik di beberapa daerah di Indonesia, walaupun pemerintah telah melakukan berbagai usaha untuk mengobati dan mencegah malaria. Pada tahun 2017, baru 266 kabupaten/ kota $(52,0 \%)$ di antara 514 kabupaten/ kota yang dinyatakan bebas malaria. Selain itu, terdapat 39 kabupaten/ kota dengan penularan tinggi yang terutama berada di kawasan timur Indonesia, yaitu Papua, Papua Barat, dan NTT. ${ }^{3}$

Pemerintah menargetkan 285 kabupaten/ kota bebas malaria pada tahun 2017, dan telah melakukan berbagai strategi untuk mengeliminasi malaria di antaranya dengan mengintensifkan penyemprotan rumah secara selektif, meningkatkan perlindungan kelompok rentan malaria (ibu hamil dan balita), meningkatkan deteksi dini malaria, pengobatan yang tepat, serta meningkatkan kesadaran dan pengetahuan masyarakat untuk melakukan upaya pencegahan malaria. Selain itu, sebagai upaya pencegahan malaria, pemerintah juga telah mendistribusikan kelambu massal ke seluruh Indonesia, pelatihan tenaga medis, dan penyediaan obat anti malaria dihidroartemisinin. Program - program tersebut terutama dilakukan di wilayah endemik tinggi malaria, yaitu Papua, Papua Barat, Maluku, dan NTT. Pada tahun 2017 Kementerian Kesehatan telah mendistribusikan 3.984.224 kelambu dalam pekan kelambu massal di 166 kabupaten/ kota di 20 provinsi di Indonesia. ${ }^{3,4}$

Pada 2016, di Papua terdapat 424.083 penderita yang diduga malaria dan 155.670 kasus yang terbukti positif malaria berdasarkan hasil pemeriksaan apusan darah. Sedangkan, jumlah 
kasus malaria di Asmat pada tahun 2016 adalah 8.737 dengan kasus terbanyak ditemukan di Distrik Der Kuomor dan Distrik Atsj. ${ }^{5}$

Kabupaten Asmat merupakan salah satu kabupaten di Papua yang terdiri atas 23 distrik dengan luas $31.983,43 \mathrm{~km}^{2}$. Asmat merupakan kabupaten yang antardistriknya dipisahkan oleh sungai dan jaraknya cukup jauh satu-sama lain. Jarak antara ibukota kabupaten dengan distrik terjauh (Suru-Suru) adalah $289 \mathrm{~km}$, sedangkan jaraknya ke distrik terdekat (Akat) adalah $37 \mathrm{~km} .{ }^{6}$ Hal tersebut sangat mempengaruhi penyebaran puskesmas dan tenaga kesehatan di tiap kecamatan. Asmat merupakan salah satu daerah dengan AMI $279 \%$, sehingga menempatkan Asmat sebagai daerah endemik tinggi dan menjadi salah satu daerah target program eliminasi malaria, ${ }^{7}$ namun sampai saat ini belum ada publikasi data terperinci terkait malaria di Asmat. Penelitian ini bertujuan untuk mengetahui prevalensi kejadian malaria di Kabupaten Asmat tahun 2017 dan untuk melihat adanya penurunan atau peningkatan kejadian malaria yang merupakan salah satu indikator evaluasi program eliminasi malaria di Indonesia.

\section{Metode}

Penelitian ini merupakan penelitian deskriptif observasional yang dilakukan selama pelaksanaan kegiatan Kuliah Kerja Nyata - Peduli Bencana (KKNPB), Universitas Gadjah Mada (UGM), pada tanggal 17 Maret hingga 30 April 2018 di Asmat. Penelitian dilakukan dengan analisis data sekunder dan data primer.

Data sekunder diambil dari Dinas Kesehatan Kabupaten Asmat, yaitu berupa laporan kunjungan di 17 puskesmas yang tersebar di kabupaten Asmat dari Januari hingga Desember 2017. Data jumlah kunjungan di setiap puskesmas selama setahun dan jumlah pasien berdasarkan jenis penyakit dicatat dan dianalisis menggunakan perangkat lunak Microsoft Excel Professional Plus 2013. Data kemudian dianalisis untuk dapat menggambarkan prevalensi kejadian malaria pada tahun 2017, dengan membagi jumlah kasus kejadian dengan total penduduk Asmat tahun 2017. Selain itu, data jumlah kasus malaria yang ditemukan di tiap distrik, jumlah kejadian malaria berdasarkan umur, dan jumlah kasus malaria per kelompok umur yang terjadi selama tahun 2017 juga digunakan untuk mengetahui persebaran kasus dan tren kejadian malaria di Asmat.

Data primer digali dengan cara observasi lingkungan dan wawancara di tiga distrik, yaitu Distrik Agats, Atsj, dan Sawaerma untuk mengetahui kemungkinan faktor-faktor risiko malaria. Observasi partisipatori dilakukan oleh Tim KKN-PB UGM PA-001 yang terdiri dari sepuluh mahasiswa Fakultas Kedokteran, Kesehatan Masyarakat, dan Keperawatan UGM, satu mahasiswa Fakultas Ekonomi UGM, dan satu mahasiswa Fakultas Geografi UGM. Subjek observasi yaitu masyarakat Asmat dengan berbagai kelompok umur (dewasa, remaja, dan anak-anak) yang tinggal di ketiga distrik tersebut, dengan komponen observasi yaitu kondisi lingkungan tempat tinggal masyarakat, kondisi rumah, pekerjaan dan keseharian masyarakat, dan pola pencarian pengobatan di masyarakat. Sedangkan subjek wawancara yaitu petugas puskesmas dan kader posyandu di kecamatan Agats, Atsj dan Sawaerma, dokter dan laboran di RSUD Agats, sekretaris dinas kesehatan, masyarakat, serta antropolog UGM yang telah lama tinggal di Agats, Ibu Dewi Linggasari. Wawancara kepada masyarakat dilakukan saat kunjungan rumah, sekaligus melakukan pengamatan kondisi rumah.

\section{Hasil}

Data kunjungan ke puskesmas dari Januari hingga Desember 2017 menunjukkan bahwa malaria masih menempati urutan ketiga penyakit terbanyak di Asmat, setelah infeksi akut pada saluran pernafasan atas dan diare (Tabel 1). Sepanjang tahun 2017 terdapat 84.134 kunjungan ke puskesmas dengan $21.247(25,3 \%)$ pasien menderita infeksi saluran pernafasan atas, 13.917 (16,5\%) menderita diare, dan 11.495 (13,6\%) menderita malaria, baik yang tegak diagnosisnya berdasarkan pemeriksaan laboratorium maupun tanpa pemeriksaan laboratorium (malaria klinis). Dengan jumlah penduduk di Asmat tahun 2017 sebesar 92.909 penduduk $^{6}$, maka didapatkan prevalensi malaria di 
kabupaten Asmat pada tahun 2017 sebesar 11.495 kasus per 92.909 penduduk (12,4\%), dengan 7.344 kasus malaria klinis (7,9\%) dan 4.151 kasus malaria didiagnosis berdasarkan hasil pemeriksaan laboratorium (4,5\%).

Dari 17 puskesmas yang tersebar di seluruh Asmat, Puskesmas Atsj merupakan puskesmas dengan jumlah penderita malaria terbanyak, yaitu sebesar 1.754 kasus malaria per 6.332 penduduk $(27,7 \%)$ diikuti oleh Puskesmas Suator, yang menyumbang 1.456 kasus per 3.495 penduduk $(41,7 \%)$ pada tahun 2017 (Gambar 1). Jumlah kasus malaria di kedua puskesmas tersebut jauh lebih tinggi dibandingkan dengan puskesmas di distrik lain, seperti di Agats dengan 331 kasus per 15.103 penduduk (2,2\%), dan Puskesmas Sawaerma

Tabel 1. Daftar 10 besar penyakit di Kabupaten Asmat pada seluruh kelompok umur periode Januari Desember 2017

\begin{tabular}{|c|c|c|c|}
\hline Jenis Penyakit & $\begin{array}{l}\text { Laki-laki, } \\
\text { n (\%) }\end{array}$ & $\begin{array}{c}\text { Perempuan, } \\
\mathrm{n}(\%)\end{array}$ & $\begin{array}{l}\text { Total, } \\
\text { n (\%) }\end{array}$ \\
\hline Infeksi akut pada saluran pernafasan bagian atas & $10.564(12,6)$ & $10.683(12,7)$ & $21.247(25,3)$ \\
\hline Diare $^{\mathrm{a}}$ & $6.910(8,2)$ & $7.007(8,3)$ & $13.917(16,5)$ \\
\hline Penyakit pada sistem otot dan jaringan pengikat & $3.917(4,7)$ & $4.166(5,0)$ & $8.083(9,6)$ \\
\hline Malaria tanpa pemeriksaan laboratorium (malaria klinis) & $3.780(4,5)$ & $3.564(4,2)$ & $7.344(8,7)$ \\
\hline Disentri & $3.497(4,2)$ & $3.448(4,1)$ & $6.945(8,3)$ \\
\hline Penyakit lain pada saluran pernafasan bagian atas & $3.383(4,0)$ & $3.538(4,2)$ & $6.921(8,2)$ \\
\hline Kecelakaan dan ruda paksa & $3.041(3,6)$ & $2.593(3,1)$ & $5.634(6,7)$ \\
\hline Observasi febris ${ }^{\mathrm{b}}$ & $2.629(3,1)$ & $2.605(3,1)$ & $5.234(6,2)$ \\
\hline Gastritis & $2.273(2,7)$ & $2.385(2,8)$ & $4.658(5,5)$ \\
\hline Malaria tropika ${ }^{c}$ & $2.134(2,5)$ & $2.017(2,4)$ & $4.151(4,9)$ \\
\hline Total & $42.128(50,1)$ & $42.006(49,9)$ & $84.134(100,0)$ \\
\hline
\end{tabular}

${ }^{a}$ Diare dengan berbagai penyebab, termasuk yang dicurigai kolera, selain disentri; ${ }^{b}$ demam dengan berbagai penyebab, kecuali akibat malaria, diare, disentri, dan infeksi saluran pernafasan; ${ }^{c}$ malaria yang disebabkan karena infeksi Plasmodium falciparum.

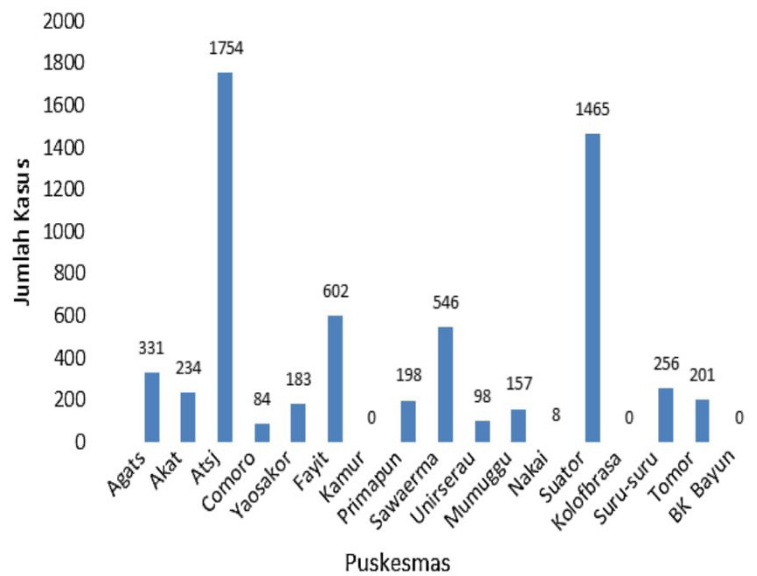

Gambar 1. Jumlah kasus malaria pada puskesmas di tiap distrik pada tahun 2017

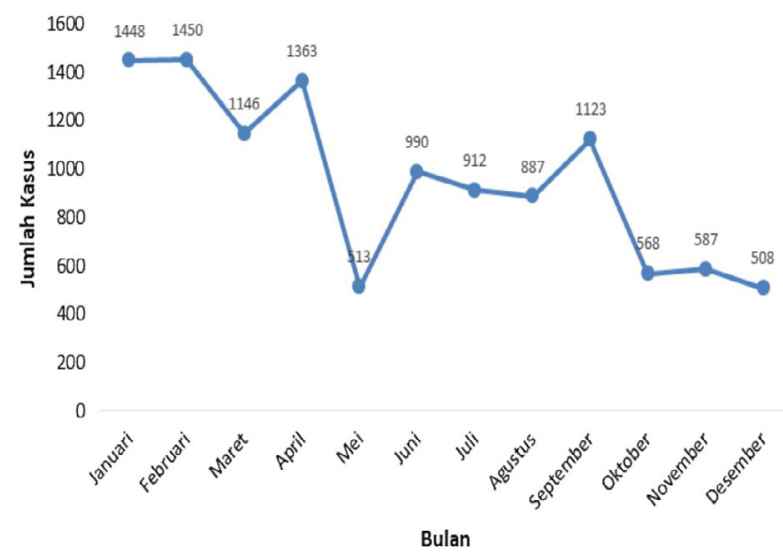

Gambar 2. Jumlah kasus malaria tiap bulan pada tahun 2017 
dengan 546 kasus per 7.198 penduduk (7,6\%).

Selain perbedaan jumlah kasus yang ditemukan di masing-masing puskesmas di distrik yang berbeda, terdapat perbedaan jumlah kasus malaria per bulannya, seperti yang terlihat di Gambar 2. Terlihat pada awal tahun (bulan Januari - April) jumlah kasus malaria lebih tinggi apabila dibandingkan dengan akhir tahun (bulan OktoberDesember) dengan jumlah kasus tertinggi di tahun 2017 yaitu pada bulan April, sebanyak 1.363 kasus, dan mengalami penurunan hingga 513 kasus pada bulan Mei.

Data kunjungan puskesmas juga memberi gambaran perbedaan jumlah kasus malaria per kelompok umur, Gambar 3 menunjukkan kasus malaria tertinggi terdapat pada kelompok umur 1 - 9 tahun (anak) sebanyak 4.338 kasus, dengan jumlah kejadian malaria pada balita yaitu 2.648 kasus dan 1.690 kasus pada anak usia $6-10$ tahun. Kasus malaria kedua terbanyak yaitu pada kelompok umur 20-59 tahun (dewasa) sebanyak 3.716 kasus.

Berdasarkan pengamatan selama pelaksanaan KKN PB UGM dari 17 Maret hingga 30 April 2018, tantangan yang dihadapi dalam pemberantasan malaria di Asmat yaitu lingkungan yang sebagian besar berupa semak-semak dan hutan sagu serta terdapat rawa pada perbatasan antardistrik (Gambar 4). Selama observasi lingkungan, ditemukan juga banyak genangan air di sekitar

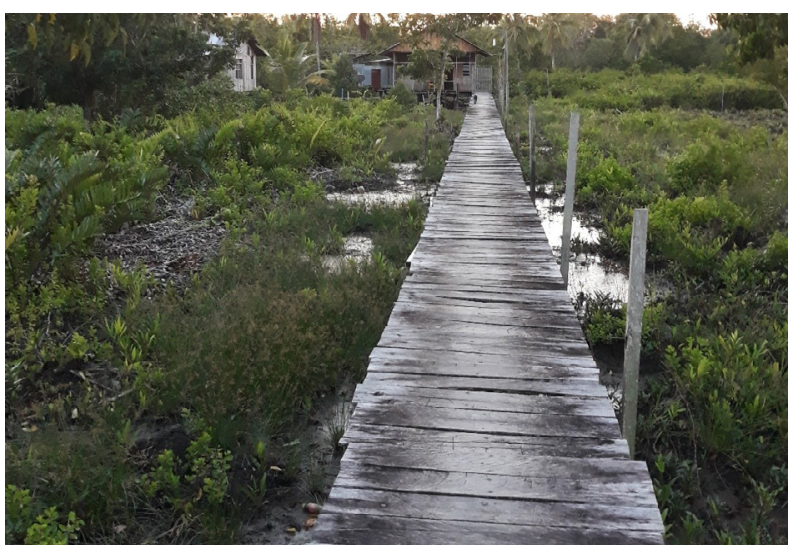

(a) pemukiman penduduk.

Faktor lingkungan lain yang kemungkinan menjadi faktor risiko malaria adalah rumahrumah penduduk yang dindingnya terbuat dari kayu dengan kerapatan yang kurang dibandingkan dengan rumah berdinding beton (Gambar 5). Selain itu, di luar faktor lingkungan, kebiasaan masyarakat Asmat yang sehari-hari pergi ke hutan untuk mencari kayu bakar atau mencari bahan makanan, dapat menjadi salah satu faktor yang mempengaruhi. Masyarakat Asmat dapat menetap hingga berminggu-minggu di bifak di dalam hutan.

Berdasarkan pengamatan, pembagian kelambu massal yang telah dilakukan pemerintah juga masih menghadapi beberapa permasalahan, salah satunya terkait dengan distribusi. Banyak kelambu belum diterima masyarakat dan hanya

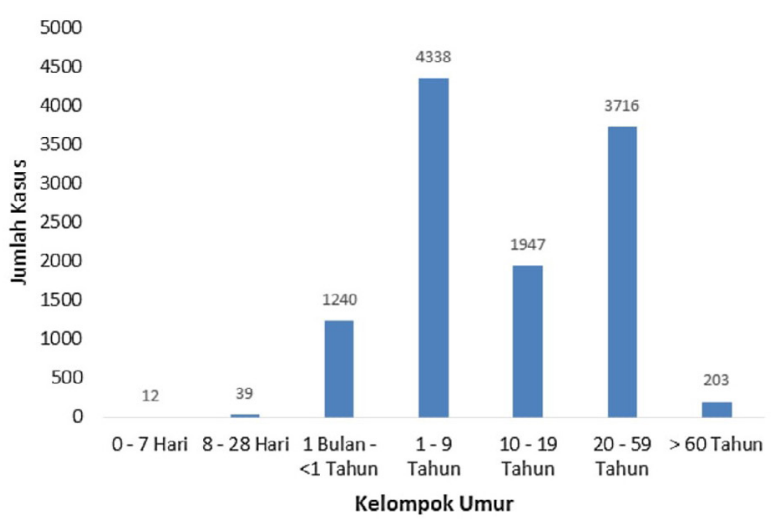

Gambar 3. Jumlah kasus malaria tiap kelompok umur pada tahun 2017, di 17 Puskesmas di Asmat

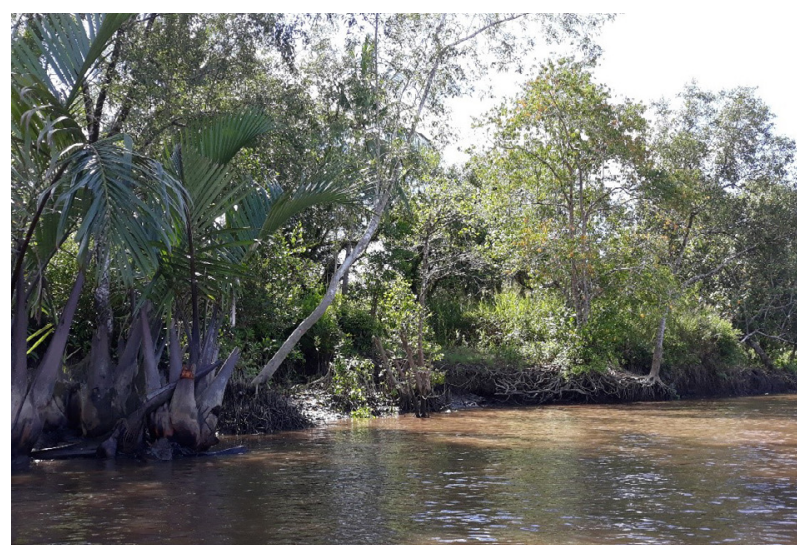

(b)

Gambar 4. Kondisi lingkungan di Agats, Asmat. (a) Lingkungan perumahan yang berada di area rawa dan penuh dengan semak-semak. (b) Hutan sagu. 
tertumpuk di gudang karena akses yang sulit ke distrik-distrik yang jauh dari pusat kota. Selain itu, kebiasaan masyarakat yang hidup berpindahpindah dan tinggal di hutan juga menyulitkan pembagian kelambu. Seperti pernyataan staf dinas kesehatan yang kami wawancarai "Di sini masih sulit untuk membagikan kelambu, karena harus dibagi rata, nanti apabila ada yang tidak dapat bisa menimbulkan pertengkaran. Untuk membagikan kelambu ke distrik yang jauh tidak bisa sering karena aksesnya sulit." Apabila sudah diterima, kelambu tidak selalu digunakan karena sebagian warga masyarakat merasa tidur dengan kelambu membuat gerah atau kurang nyaman. Masih perlu penelitian lebih lanjut untuk dapat benar-benar menelaah hubungan pengunaan kelambu dengan kejadian malaria di Asmat.

Selain itu perilaku pencarian pengobatan pada masyarakat juga berpengaruh terhadap jumlah kejadian malaria. Berdasarkan wawancara dengan petugas kesehatan di kabupaten Asmat, masih dijumpai warga masyarakat yang pergi memeriksakan diri ke dokter untuk meminta obat tetapi di rumah obatnya tidak diminum, atau diminum namun tidak sesuai dosisnya. Selain itu masih ada masyarakat yang mempercayai penggunaan ramuan-ramuan tradisional dari dedaunan sebagai obat, seperti yang diutarakan dokter yang bekerja di RSUD Agats "Masih ada yang menggunakan daun-daunan sebagai

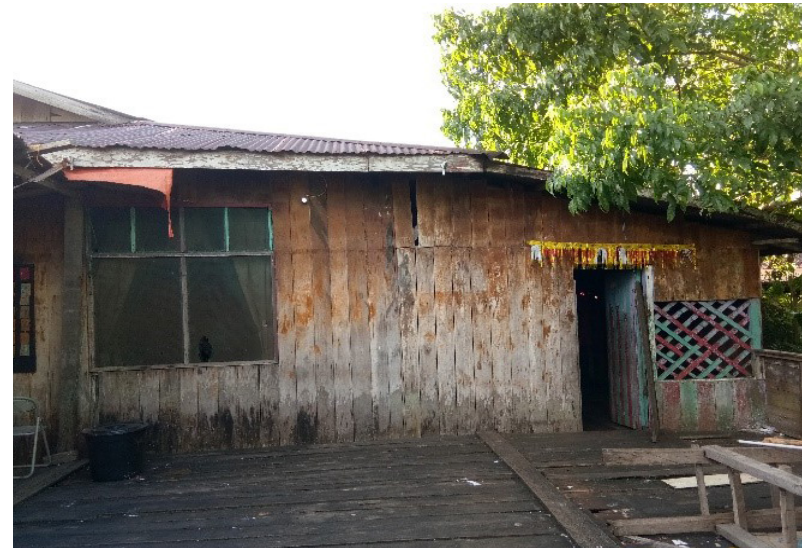

Gambar 5. Rumah-rumah penduduk di Agats, Asmat, kebanyakan dindingnya terbuat dari papan kayu dengan kerapatan kurang obat, terutama di distrik-distrik. Kalau di Agats masyarakat sudah mulai datang ke sini (RS) untuk mencari obat, tapi masih banyak yang setelah periksa datang lagi dengan keluhan yang sama, setelah dicek ternyata obatnya tidak diminum. Atau diminum sekaligus." Hal tersebut memengaruhi sulitnya mengeliminasi sumber penularan malaria di komunitas.

Berdasarkan data yang didapatkan dari Tentara Nasional Indonesia (TNI) yang bertugas mengatasi kejadian luar biasa di Asmat, dari seluruh puskesmas di Asmat, hanya empat puskesmas yang memiliki dokter umum, sisanya hanya dikelola oleh mantri atau perawat. Empat puskesmas yang memiliki dokter umum adalah Puskesmas Agats, Suru-suru, Primapun, dan Basim. Pemeriksaan laboratorium untuk malaria yang tersedia di puskesmas juga terbatas. Kebanyakan puskesmas hanya menyediakan rapid diagnostic test malaria. Pemeriksaan apusan darah tepi jarang dilakukan di puskesmas. Pemeriksaan tersebut hanya rutin dilakukan di RSUD Agats. Banyaknya kasus malaria yang terjadi juga membuat alat rapid diagnostic test malaria di puskesmas sering habis, seperti yang sering terjadi di distrik Sawaerma yang menjadi wilayah studi penelitian ini. Kendala stok tersebut juga membuat banyak kasus malaria yang didiagnosis hanya berdasarkan pemeriksaan klinis dan tanpa pemeriksaan penunjang.

\section{Pembahasan}

Sebagai upaya pemberantasan malaria, WHO telah mencanangkan Global Technical Strategy for Malaria 2016-2030 yang telah diadopsi oleh pemerintah Indonesia menjadi beberapa program pemberantasan malaria. Upaya pencegahan yang dianggap paling efektif oleh Kementerian Kesehatan Republik Indonesia adalah pembagian kelambu, penyemprotan dinding rumah, dan pengunaan repellent. Upaya lain yang juga dilakukan adalah menebarkan ikan pemakan jentik, seperti ikan mujair dan cupang, pelatihan tenaga malaria (dokter, perawat, analis, kader, petugas surveilans, dan entomolog), serta penyediaan obat anti malaria. ${ }^{3}$ Walaupun berbagai program 
tersebut telah dijalankan sepanjang tahun 2017, terlihat adanya peningkatan kejadian malaria di kabupaten Asmat, dari 8.737 kasus malaria per 90.316 penduduk $(9,7 \%)$ yang dilaporkan tahun $2016^{8}$, menjadi 11.495 kasus per 92.909 penduduk $(12,4 \%)$ pada tahun 2017.

Peningkatan kejadian malaria pada tahun 2017 dapat berhubungan dengan berbagai hal, yaitu perilaku masyarakat sekitar, lingkungan, dan ketersediaan pelayanan kesehatan yang memadai. Kurniawan ${ }^{7}$ dan Mirino ${ }^{9}$ memaparkan faktor-faktor yang berhubungan dengan kejadian malaria, yaitu lingkungan fisik, biologi, kimia dan perilaku serta pengetahuan masyarakat. Lingkungan fisik yang memengaruhi antara lain adalah suhu, kelembaban, kerapatan dinding rumah, pengunaan kawat kassa pada ventilasi rumah, adanya parit atau kolam di sekitar rumah dan juga curah hujan. Lingkungan biologi, seperti semak-semak dan rawa-rawa, serta adanya ikan pemangsa jentik seperti ikan mujair dan ikan cupang. Sedangkan lingkungan kimia yang mempengaruhi adalah salinitas dan $\mathrm{pH}^{7,9}$

Suhu dan kelembaban merupakan salah satu faktor lingkungan yang berhubungan dengan cuaca yang berubah sepanjang tahunnya, dan berhubungan dengan perbedaan tren kejadian malaria di tahun 2017 seperti yang tergambar pada Gambar 2. Curah hujan yang cukup tinggi, sekitar 3.000 - 5.000 milimeter per tahun, dengan hari hujan sekitar 200 hari per tahun dapat membentuk genangan air di sekitar area rumah penduduk yang cocok bagi nyamuk Anopheles untuk berkembang biak. $^{7,9}$ Faktor lingkungan lain yang kemungkinan menjadi faktor risiko malaria adalah rumahrumah penduduk yang dindingnya terbuat dari kayu dengan kerapatan yang kurang dibandingkan dengan rumah berdinding beton. Selain itu masih banyak rumah yang tidak memakai kawat kassa pada ventilasi meskipun pemerintah setempat telah menggalakkan penggunaan kawat kassa, terutama di rumah-rumah gratis yang dibangun oleh pemerintah. 7,9

Lingkungan daerah Asmat yang cocok untuk tempat berkembang biak nyamuk Anopheles dan rumah penduduk yang masih belum memakai kawat kassa dapat menjadi faktor yang menyulitkan eliminasi malaria di daerah tersebut. Selain itu, aktivitas harian masyarakat pergi ke hutan juga meningkatkan risiko tergigit nyamuk vektor malaria, terutama pada malam hari.?

Risiko tergigit meningkat pada malam hari karena sebagian besar nyamuk bersifat krepuskular (aktif pada senja atau fajar) atau nokturnal (aktif pada malam hari) sehingga nyamuk lebih sering menghisap darah mulai pukul 18:00 hingga pukul 06:00, dengan puncaknya pada pukul 24:00 hingga 01:00. Contohnya, An. barbirostris dan An. subpictus merupakan jenis yang menghisap darah sepanjang malam, antara pukul $18.00-06.00$, sedangkan $A n$. vagus mulai menghisap darah pukul 22:00 hingga 23:00. ${ }^{10,11}$ Masyarakat juga jarang menggunakan repellent anti nyamuk maupun pakaian tertutup untuk melindungi diri dari nyamuk, bahkan banyak anak-anak yang terbiasa tidak memakai baju maupun celana. ${ }^{7}$ Kebiasaan memakai baju masih susah ditanamkan pada anak-anak, terutama pada anak-anak yang berada di distrik yang jauh dari ibukota.

Tabel 1 menunjukkan bahwa sebagian besar $(63,9 \%)$ kasus malaria hanya ditegakkan berdasarkan pemeriksaan klinis tanpa pemeriksaan laboratorium. Penegakan diagnosis berdasar pemeriksaan klinis saja dapat menyebabkan overdiagnosis malaria. Laporan profil kesehatan Provinsi Papua tahun 2016 menunjukkan bahwa dari 6.553 kasus terduga malaria, hanya 4.330 $(66,1 \%)$ kasus yang terbukti positif berdasarkan pemeriksaan apusan darah tepi. ${ }^{5}$ Sehingga masih terdapat kemungkinan prevalensi kejadian malaria yang dilaporkan lebih tinggi dibandingkan prevalensi yang sebenarnya. Hal tersebut berkaitan dengan ketidaktersediaan layanan kesehatan di Asmat yang disebabkan oleh sulitnya akses menuju ke tiap distrik. Layanan kesehatan di Asmat juga masih memiliki keterbatasan baik dalam jumlah tenaga kesehatan maupun ketersediaan peralatan medis.

Jumlah kasus malaria tertinggi dijumpai di Puskesmas Atsj yaitu sebanyak 1.754 kasus. Kasus malaria di Puskesmas Atsj pada tahun 
2017 sebenarnya sudah mengalami penurunan dibandingkan tahun sebelumnya dimana terdapat 2.253 kasus, namun jumlah tersebut masih terlihat sangat mencolok dibandingkan jumlah kasus di puskesmas lainnya. Di Puskesmas Agats dan Sawaerma, berturut-turut hanya dijumpai 331 kasus dan 546 kasus, padahal kedua distrik tersebut mempunyai jumlah penduduk yang lebih banyak. Atsj memiliki luas wilayah $1.261,0 \mathrm{~km}^{2}$, Agats 702,0 $\mathrm{km}^{2}$, dan Sawaerma $3.084,5 \mathrm{~km}^{2}$. Agats memiliki jumlah penduduk paling banyak yaitu 15.103 jiwa, diikuti oleh Sawaerma dan Atsj sebanyak 7.198 jiwa dan 6.332 jiwa. ${ }^{6}$ Di antara ketiga distrik tersebut, kepadatan penduduk di Agats paling tinggi (21,5 jiwa/ $\mathrm{km}^{2}$ ), namun ternyata justru mempunyai jumlah kasus malaria yang terendah. Rendahnya kasus malaria di Agats berhubungan dengan tingkat kesejahteraan yang lebih baik di distrik Agats apabila dibandingkan kedua distrik lainnya. Angka kemiskinan di Agats merupakan yang terendah di Asmat ${ }^{6}$ sehingga Agats memiliki status gizi dan sanitasi yang lebih baik dibanding kedua distrik lainnya.

Jumlah kasus malaria yang tinggi di Atsj dapat disebabkan karena Puskesmas Atsj merupakan puskesmas yang cukup besar sehingga sering dijadikan rujukan oleh puskesmas-puskesmas di distrik lain. Tidak menutup kemungkinan, kasus malaria yang dilaporkan di Puskesmas Agats lebih sedikit karena di Agats terdapat RSUD, sehingga kebanyakan penderita malaria langsung memeriksakan diri ke RSUD. Selain itu, di Agats akses terhadap obat-obatan lebih mudah karena terdapat cukup banyak apotek yang tersebar merata dan untuk membeli obat malaria tidak dibutuhkan resep dokter. Hal ini memungkinkan masyarakat untuk langsung membeli obat malaria saat merasakan gejala - gejala seperti demam sehingga tidak datang untuk memeriksakan diri ke puskesmas. Perilaku pencarian pengobatan di masyarakat Asmat dapat menjadi topik yang menarik untuk diteliti lebih lanjut.

Pada penelitian ini terlihat kasus malaria tertinggi terdapat pada kelompok umur 1-9 tahun (anak) sebanyak 4.338 kasus, dengan jumlah kejadian malaria sepanjang tahun 2017 pada balita yaitu 2.648 kasus. Perencanaan program pencegahan malaria selanjutnya perlu mempertimbangkan anak, terutama balita, sebagai salah satu fokus populasi target pencegahan malaria karena anak di Asmat termasuk kelompok yang rentan terjangkit malaria dibandingkan kelompok umur lainnya.

Balita merupakan salah satu kelompok yang memiliki risiko tinggi terkena malaria selain wanita hamil, terutama balita dengan gizi kurang. Balita dengan gizi kurang, seperti yang baru saja menjadi sorotan di kabupaten Asmat, memiliki risiko 3,5 kali mengalami kesakitan dan kematian dibandingkan balita cukup gizi. Penyakit infeksi seperti malaria juga dapat mempengaruhi status gizi balita karena penurunan imunitas dan nafsu makan. ${ }^{12}$ Keterkaitan antara tingginya kejadian malaria dengan status gizi balita di Asmat perlu diteliti lebih lanjut.

Penelitian ini memiliki beberapa kelemahan, yaitu prevalensi pada penelitian ini kemungkinan lebih rendah daripada prevalensi yang sebenarnya karena jumlah kasus di RSUD Agats dan jumlah kasus yang tidak memeriksakan diri tidak terdata. Selain itu masih dibutuhkan penelitian lanjutan mengenai faktor yang mempengaruhi tingginya kejadian malaria di distrik Atsj, agar dapat menjadi masukan penanganan malaria selanjutnya yang dapat dilakukan di daerah tersebut.

\section{Kesimpulan}

Prevalensi kasus malaria di kabupaten Asmat pada tahun 2017 yaitu sebanyak 12,4\%, meningkat daripada tahun sebelumnya. Hal tersebut menunjukkan bahwa penanganan malaria masih menjadi tantangan besar bagi petugas kesehatan dan pemerintah karena program-program yang selama ini dijalankan belum efektif menurunkan kejadian malaria. Perlu dilakukan penelitian lebih lanjut untuk melengkapi kekurangan yang masih didapatkan pada penelitian ini dan mengetahui penyebab pasti masih tingginya kejadian malaria agar kebijakan yang diambil lebih tepat. Selain itu diperlukan pendekatan multisektoral dalam penanganan malaria, baik dalam upaya promotif, preventif, maupun kuratif. 


\section{Ucapan terima kasih}

Terima kasih penulis ucapkan kepada berbagai pihak yang telah mendukung dan memberikan fasilitas sehingga penelitian ini dapat terlaksana, yaitu Direktorat Pengabdian Kepada Masyarakat (DPKM) UGM, pemerintah Kabupaten Asmat, kakak-kakak pengurus pondokan KKN-PB UGM PA-001, dan anggota tim KKN-PB UGM PA-001 yang lain (Fazlur Risyad Laochi, Herdhina Dwi Jawanti, Jendi Alfian Alza, Arum Rarasati, Aurelia Maria Ozora Diomarizka, Nadia Adelin, Muhlifain Nauminingtyas, dan Dyan Puspitasari). Terima kasih juga kami ucapkan kepada Dinas Kesehatan Kabupaten Asmat, kader Puskesmas di Agats, Atsj, dan Sawaerma atas bantuan yang diberikan dalam pengambilan data.

\section{Daftar pustaka}

1. World Health Organization. World malaria report 2017. Geneva: World Health Organization; 2017. 196 p.

2. World Health Organization. Global technical strategy for malaria 2016-2030 [Internet]. Geneva: World Health Organization; 2015 [cited 2018 Aug 23]. 35 p. Available from: http://apps.who.int/iris/bitstream/ handle/10665/176712/9789241564991_eng. pdf?sequence $=1$

3. Kementerian Kesehatan Republik Indonesia. Wilayah Indonesia dominan bebas malaria [Internet]. Jakarta: Kementerian Kesehatan Republik Indonesia; 2018 [updated 2018 April 23; cited 2018 Aug 23]. Available from: http://www.depkes.go.id/article/ view/18042400002/wilayah-indonesiadominan-bebas-malaria.html

4. Pusat Data dan Informasi Kementerian Kesehatan Republik Indonesia. Info data malaria. Jakarta: Pusat Data dan Informasi Kementerian Kesehatan Republik Indonesia; 2016. 8p.

5. Dinas Kesehatan Provinsi Papua. Profil kesehatan Provinsi Papua tahun 2016. Jayapura, Papua: Dinas Kesehatan Provinsi
Papua; 2017. 163 p.

6. Badan Pusat Statistik Kabupaten Asmat. Kabupaten Asmat dalam angka 2018. Asmat, Papua: Badan Pusat Statistik Kabupaten Asmat; 2018.

7. Kurniawan J. Analisis faktor risiko lingkungan dan perilaku penduduk terhadap kejadian malaria di Kabupaten Asmat tahun 2008 [master's thesis]. Semarang: Universitas Diponegoro; 2008. 147 p.

8. Badan Pusat Statistik Kabupaten Asmat. Kabupaten Asmat dalam angka 2017. Asmat, Papua: Badan Pusat Statistik Kabupaten Asmat; 2017.

9. Mirino R. Studi faktor lingkungan rumah dan perilaku masyarakat yang berhubungan dengan kejadian malaria di Kecamatan Agats Kabupaten Asmat Papua 2009 [master's thesis]. Semarang: Universitas Diponegoro; 2009. 128 p.

10. Rahmawati E, Hadi U, Soviana S. Keanekaragaman jenis dan perilaku menggigit vektor malaria (Anopheles spp.) di Desa Lifuleo, Kecamatan Kupang Barat, Kabupaten Kupang, Nusa Tenggara Timur. J Entomol Indones. 2014;11(2):53-64.

11. Hasyim H, Camelia A, Alam NF. Determinan kejadian malaria di wilayah endemik Provinsi Sumatera Selatan. Jurnal Kesehatan Masyarakat Nasional. 2014;8(7):291-4.

12. Tarmidzi M, Soesanto T, Sudargo T. Hubungan antara kejadian malaria dengan status gizi balita. Berita Kedokteran Masyarakat. 2007;23(1):41-6. 